\title{
Molecular design of luminescent metal-based materials*
}

\author{
Vivian Wing-Wah Yam \\ Department of Chemistry, The University of Hong Kong, Pokfulam Road, \\ Hong Kong, People's Republic of China
}

\begin{abstract}
A series of soluble di- and polynuclear transition-metal acetylides with rich luminescence behavior have been designed and successfully isolated. The photophysical and photochemical properties have been studied. Luminescent polynuclear metal complexes have also been obtained based on the metal chalcogenide building block. These high-nuclearity transition-metal chalcogenide complexes have been structurally characterized and shown to display rich luminescence behavior. Various approaches and strategies to design and synthesize luminescent polynuclear metal complexes that may find potential applications as chemosensors and luminescence signalling devices will also be described.
\end{abstract}

\section{INTRODUCTION}

Since the well-known discovery of luminescence and excited-state properties associated with dinuclear $\mathrm{d}^{8}-\mathrm{d}^{8}$ metal complexes [1], the importance of metal-metal interaction and its bond establishment in the excited state has stimulated wide interest in the studies of luminescent polynuclear metal complexes, and in particular, an extension of investigations into the related $\mathrm{d}^{10}-\mathrm{d}^{10}$ metal complexes [2]. Polynuclear $\mathrm{d}^{10}$ metal complexes have been shown to display interesting structural features, in which short metal-metal distances are usually found to be associated with these complexes [3]. The short metal-metal contacts between these closed-shell $\mathrm{d}^{10}$ metal centers are a consequence of the relativistic effects. Theoretically, in the absence of $(n+1) s$ and $(n+1) p$ functions, interaction between the closedshell $\mathrm{d}^{10}$ centers are repulsive in nature. However, configuration mixing of the filled nd-orbitals with the empty orbitals derived from higher energy $(n+1) s$ and $(n+1) p$ orbitals may establish some weak metal-metal interaction. In general, short metal-metal contacts do not necessarily indicate the presence of $d^{10}-d^{10}$ bonding interaction, especially under the influence of the bridging ligands. Nevertheless, the possibility of bonding interaction between closed-shell $\mathrm{d}^{10}$ metal centers is still attracting a lot of interest.

The recent reports on the potential applications of alkynyl metal complexes as nonlinear optical materials, molecular wires and rigid-rod materials, and the wide variety of possible bonding modes of the alkynyl moiety have aroused our interest in investigating their potential in the design and synthesis of di- and polynuclear metal complexes. Similarly, transition-metal chalcogenides are known to exist in a wide variety of molecular structures with very diverse bonding modes. It is believed that chalcogens are also attractive candidates for the design of polynuclear $\mathrm{d}^{10}$ metal systems. Although a large number of transition-metal chalcogenide clusters and organometallic aggregates of $\mathrm{d}^{10}$ metal centers containing short metal-metal contacts are known in the literature, and the spectroscopic and photophysical properties of semiconducting insoluble $\mathrm{d}^{10}$ metal chalcogenide materials have attracted a lot of interests, related studies on the photoluminescence behavior of soluble molecular species are extremely limited

*Lecture presented at the XVIII ${ }^{\text {th }}$ IUPAC Symposium on Photochemistry, Dresden, Germany, 22-27 July 2000. Other presentations are published in this issue, pp. 395-548. 
and remain relatively unexplored. Thus, the design and luminescence studies of soluble molecular chalcogenido and alkynyl clusters of selected metals with various nuclearities would represent an interesting area of research. Extension of the work to the design of luminescent polynuclear metal complexes that may find potential applications as chemosensors and luminescence signalling devices would also be a worthwhile and challenging direction for the photochemists to explore.

\section{LUMINESCENT TRANSITION-METAL ACETYLIDES}

\section{Copper(I) acetylides}

The triangulo- $\mathrm{Cu}_{3}$ complexes, $\left[\mathrm{Cu}_{3}(\mathrm{P}-\mathrm{P})_{3}\left(\mu_{3}-\eta^{1}-\mathrm{C} \equiv \mathrm{CR}\right)_{2}\right]^{+}$and $\left[\mathrm{Cu}_{3}(\mathrm{P}-\mathrm{P})_{3}\left(\mu_{3}-\eta^{1}-\mathrm{C} \equiv \mathrm{CR}\right)\right]^{2+}$, have been prepared by the reaction of the binuclear complex $\left[\mathrm{Cu}_{2}(\mathrm{P}-\mathrm{P})_{2}(\mathrm{MeCN})_{2}\right]^{2+}$ with $\mathrm{RC} \equiv \mathrm{CH}$ in the presence of $\mathrm{KOH}$ or ${ }^{\mathrm{n}} \mathrm{BuLi}$ in the appropriate ratio under anaerobic and anhydrous conditions $\left(\mathrm{P}-\mathrm{P}=\mathrm{Ph}_{2} \mathrm{PCH}_{2} \mathrm{Ph}_{2}\right.$ (dppm); $\mathrm{Ph}_{2} \mathrm{PN}\left(\mathrm{R}^{\prime}\right) \mathrm{PPh}_{2}, \mathrm{R}^{\prime}=\mathrm{Ph},{ }^{n} \mathrm{Pr}, \mathrm{C}_{6} \mathrm{H}_{4}-\mathrm{CH}_{3}-4$ ) (Scheme 1) [4]. The electronic absorption spectra of these complexes are dominated by high-energy absorptions, typical of intraligand IL(diphosphine) and IL(acetylide) transitions with low-energy shoulders tailing to ca. $400 \mathrm{~nm}$. Excitation of these complexes in the solid state and in fluid solutions results in long-lived and intense luminescence. In general, the complexes with electron-rich acetylides emit at a lower energy. For example, the emission energies of $\left[\mathrm{Cu}_{3}(\mathrm{dppm})_{3}\left(\mu_{3}-\eta^{1}-\mathrm{C} \equiv \mathrm{C}-\mathrm{R}\right)\right]^{2+}$ in acetone solution follow the order: $\mathrm{R}=\mathrm{C}_{6} \mathrm{H}_{4}-\mathrm{OCH}_{3}-4$ $(483 \mathrm{~nm}) \approx \mathrm{Ph}(499 \mathrm{~nm})>\mathrm{C}_{6} \mathrm{H}_{4}-\mathrm{NH}_{2}-4(504,564 \mathrm{~nm})>{ }^{t} \mathrm{Bu}(640 \mathrm{~nm}) \approx{ }^{n} \mathrm{C}_{6} \mathrm{H}_{13}(650 \mathrm{~nm})$ [4c,f], in line with the increasing donating ability of the acetylide ligand. The origin of the emission has been proposed to involve substantial ligand-to-metal charge-transfer (LMCT) [acetylide $\rightarrow \mathrm{Cu}_{3}$ ] character, with mixing of some metal-centerd $3 \mathrm{~d}^{9} 4 \mathrm{~s}^{1}$ character in view of the short $\mathrm{Cu}-\mathrm{Cu}$ distances, especially in the case of the bi-capped acetylide species. Besides, the mono-capped species have been found to emit at a lower energy than the bi-capped analogues with the same acetylide ligand [4c,f]. For example, the emission energy of $\left[\mathrm{Cu}_{3}(\mathrm{dppm})_{3}\left(\mu_{3}-\eta^{1}-\mathrm{C} \equiv \mathrm{C}-{ }^{t} \mathrm{Bu}\right)\right]^{2+}(640 \mathrm{~nm})$ is lower than that of $\left[\mathrm{Cu}_{3}(\mathrm{dppm})_{3}\left(\mu_{3}-\eta^{1}-\mathrm{C} \equiv \mathrm{C}-{ }^{t} \mathrm{Bu}\right)_{2}\right]^{+}(580 \mathrm{~nm})$ in degassed acetone. It is likely that the higher overall positive charge of the mono-capped acetylide complexes relative to those of the bi-capped species would stabilize the essentially metal-centered LUMO, leading to a lower-lying LMCT emissive state. Overall speaking, the lowest-lying emissive state could be best described as an admixture of LMCT triplet state and a metal-centered MC $3 \mathrm{~d}^{9} 4 \mathrm{~s}^{1}$ state modified by copper-copper interaction. The relative degrees of the LMCT and MC character depend on the nature of the acetylide ligand as well as the extent of metal-metal interaction. Recently, extension of the work to the diynyl system, $\left[\mathrm{Cu}_{3}(\mathrm{P}-\mathrm{P})_{3}\left(\mu_{3}-\eta^{1}-\mathrm{C} \equiv \mathrm{C}-\mathrm{C} \equiv \mathrm{CR}\right)_{2}\right]^{+}$and $\left[\mathrm{Cu}_{3}(\mathrm{P}-\mathrm{P})_{3}\left(\mu_{3}-\eta^{1}-\mathrm{C} \equiv \mathrm{C}-\mathrm{C} \equiv \mathrm{CR}\right)\right]^{2+}$, has also been accomplished in our laboratory.

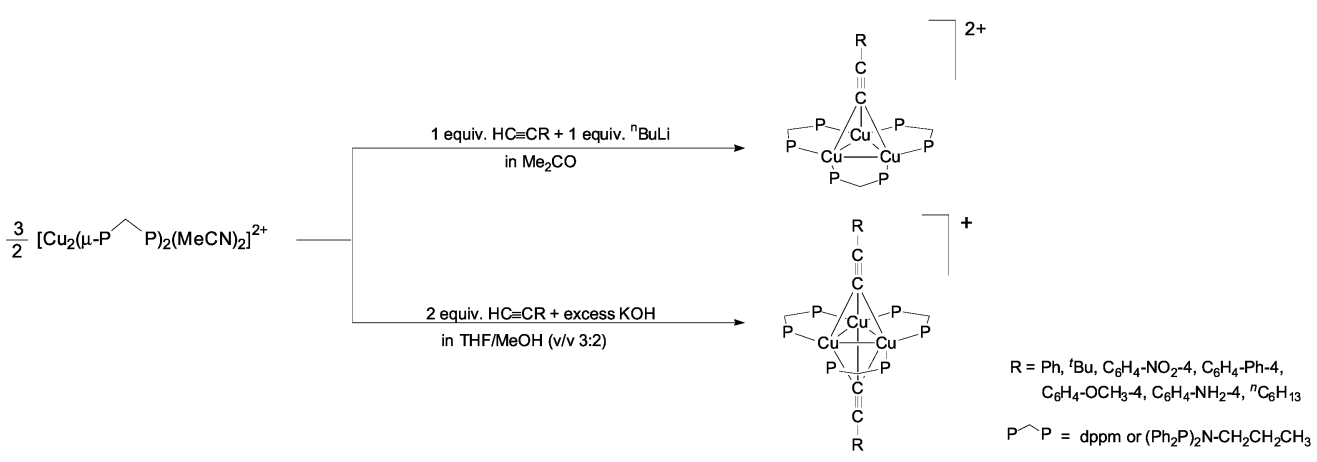

Scheme 1

Luminescent tetranuclear and hexanuclear copper(I) acetylide complexes have also been prepared (Scheme 2) [4e,5]. In all cases, the excited states of the complexes have been proposed to bear a substantial ${ }^{3} \mathrm{LMCT}$ (acetylide $\rightarrow \mathrm{Cu}$ ) character, and probably mixed with a metal-centered d-s triplet-state 
[5,6]. In view of the highly structured emission bands with vibrational progressional spacings typical of $v(\mathrm{C} \cdots \mathrm{C})$ stretches of the aromatic ring and the exceptionally long lifetimes observed for the hexanuclear complex $\left[\mathrm{Cu}_{3}(\mathrm{dppm})_{3}\left(\mu_{3}-\eta^{1}-\mathrm{C} \equiv \mathrm{C}-\mathrm{C}_{6} \mathrm{H}_{4}-\mathrm{C} \equiv \mathrm{C}-4\right) \mathrm{Cu}_{3}(\mu-\mathrm{dppm})_{3}\right]^{4+}[4 \mathrm{e}]$, the possibility of an involvement of a ligand-centered $\pi-\pi^{*}$ (acetylide) excited state has not been ruled out.

Scheme 2

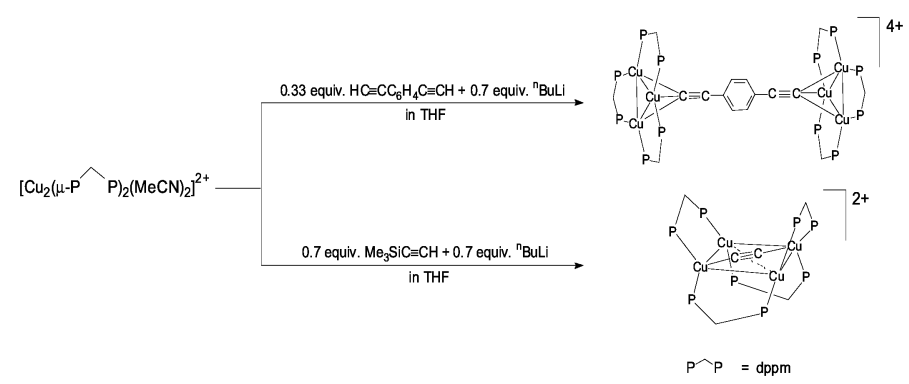

\section{Rhenium(I) acetylides}

Despite the metal-to-ligand charge transfer (MLCT) excited-state chemistry of rhenium(I) polypyridines have been extensively explored [6] and that there were examples of rhenium acetylides in the literature [7], there were no reports on luminescent rhenium(I) acetylide complexes. Luminescent mono- and dinuclear rhenium(I) acetylide complexes, $\left.\left[\operatorname{Re}(\mathrm{CO})_{3}(\mathrm{~N}-\mathrm{N})(\mathrm{C} \equiv \mathrm{C})_{\mathrm{n}} \mathrm{R}\right)\right]$ and $\left[(\mathrm{N}-\mathrm{N})(\mathrm{CO})_{3} \mathrm{Re}-(\mathrm{C} \equiv \mathrm{C}-\mathrm{C} \equiv \mathrm{C})_{\mathrm{n}}-\mathrm{Re}(\mathrm{CO})_{3}(\mathrm{~N}-\mathrm{N})\right]\left(\mathrm{n}=1 ; \mathrm{N}-\mathrm{N}=\right.$ bpy, ${ }^{t} \mathrm{Bu}_{2}$ bpy, $\mathrm{Me}_{2}$ bpy, phen) were first synthesized in our laboratory (Scheme 3) [8]. Extension of the work to higher acetylides $(n=2,3)$ has also been accomplished [9].

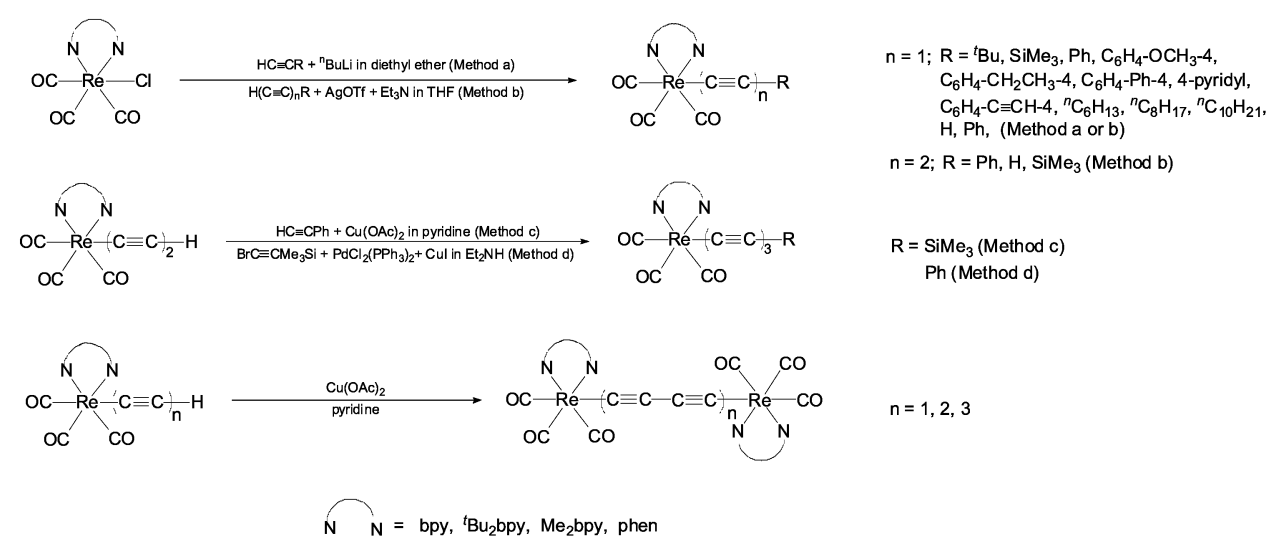

Scheme 3

\section{LUMINESCENT TRANSITION-METAL CHALCOGENIDES}

\section{Copper(I) and silver(I) chalcogenides}

Tetranuclear copper(I) and silver(I) complexes with $\mu_{4}$-bridging chalcogenides, $\left[\mathrm{M}_{4}(\mathrm{P}-\mathrm{P})_{4}\left(\mu_{4}-\mathrm{E}\right)\right]^{2+}$ $\{\mathrm{M}=\mathrm{Cu}, \mathrm{E}=\mathrm{S}, \mathrm{Se} ; \mathrm{M}=\mathrm{Ag}, \mathrm{E}=\mathrm{S}, \mathrm{Se}, \mathrm{Te} ; \mathrm{P}-\mathrm{P}=$ bis(diphenylphosphino)methane (dppm), bis[bis(4-methylphenyl)phosphino]methane (dtpm)\}, were synthesized in our laboratory and shown to exhibit rich luminescence behavior (Scheme 4) [10]. In general, the solid-state emission energies were found to follow the order: $\mathrm{E}=\mathrm{S}>\mathrm{Se}>\mathrm{Te}$ and $\mathrm{M}=\mathrm{Ag}>\mathrm{Cu}$ (Fig. 1). For example, the solid samples of 


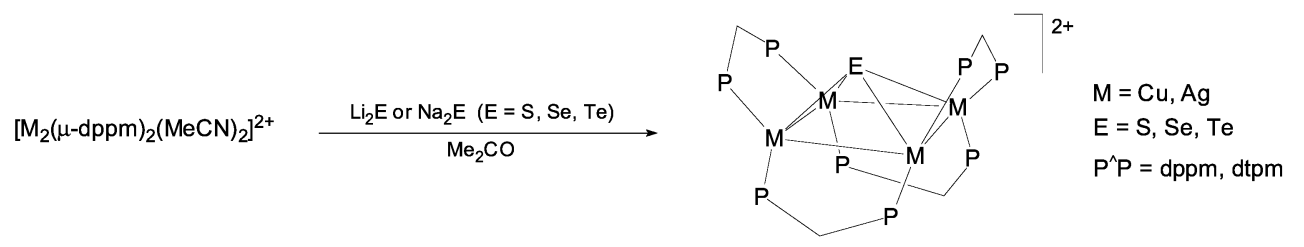

\section{Scheme 4}

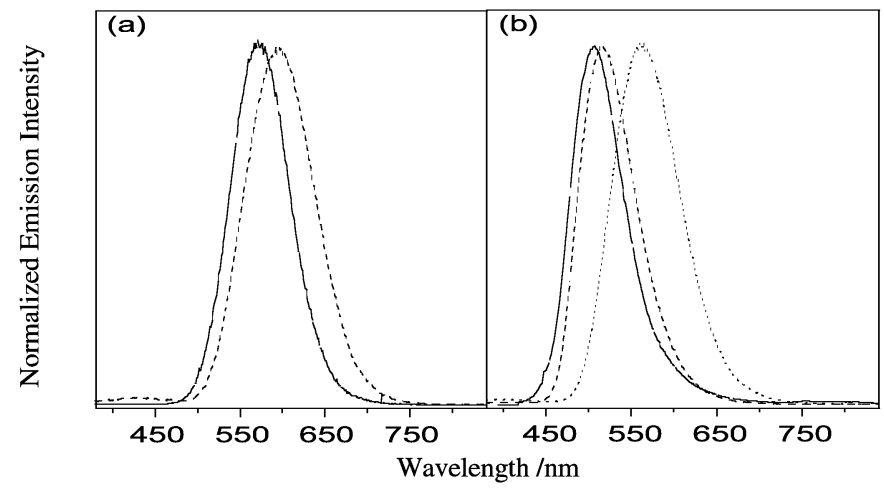

Fig. 1 Solid-state emission spectra of $\left[M_{4}(\mu-d p p m)_{4}\left(\mu_{4}-\mathrm{E}\right)\right]^{2+}$ (a) $\mathrm{E}=\mathrm{S} ; \mathrm{M}=\mathrm{Cu}(-----), \mathrm{M}=\mathrm{Ag}(-)$ and (b) $\mathrm{M}=\mathrm{Ag}$; $\mathrm{E}=\mathrm{S}(-) ; \mathrm{E}=\mathrm{Se}(-----) ; \mathrm{E}=\mathrm{Te}(\cdots \cdots \cdots)$.

the complexes $\left[\mathrm{Ag}_{4}(\mu-\mathrm{dppm})_{4}\left(\mu_{4}-\mathrm{E}\right)\right]^{2+}$ emit at $516(\mathrm{E}=\mathrm{S}), 527 \mathrm{~nm}(\mathrm{E}=\mathrm{Se})$ and $574 \mathrm{~nm}(\mathrm{E}=\mathrm{Te})$. This energy trend is in line with the ionization energies of the chalcogens and supports the excited-state assignment of large LMCT $\left[\mathrm{E}^{2-} \rightarrow \mathrm{Ag}_{4}\right.$ ] character. Similar to the acetylide systems [4e], the red shift in emission energies upon going from the silver(I) to the copper(I) analogs is ca. $0.27 \mathrm{eV}$. The lowest lying excited states of these clusters have been assigned to originate from a ligand-to-metal charge-transfer (LMCT) $\left[\mathrm{E}^{2-} \rightarrow \mathrm{M}_{4}\right]$ triplet state mixed with a metal-centered (ds/dp) character, which have also been supported by ab initio molecular orbital calculation [10b].

These complexes have also been found to undergo facile photo-oxidative electron-transfer reactions with a series of pyridinium acceptors, indicative of their highly reducing nature in the excited states. An excited-state reduction potential, $E^{\circ}\left\{\left[\mathrm{Cu}_{4}\right]^{3+} /\left[\mathrm{Cu}_{4}\right]^{2+*}\right\}$ of $-1.55(10) \mathrm{V}$ vs. S.S.C.E. has been estimated for $\left[\mathrm{Cu}_{4}(\mathrm{dppm})_{4}\left(\mu_{4}-\mathrm{Se}\right)\right]^{2+}$ with a reorganization energy $\lambda$ of $1.12(10) \mathrm{eV}$. The excited-state properties of these clusters have also been probed by nanosecond laser flash photolysis studies [10c].

\section{Gold(I) chalcogenides}

As a continuation of our efforts in the photophysical and photochemical studies of polynuclear $\mathrm{d}^{10}$ metal chalcogenide systems, we recently isolated two novel series of luminescent gold(I) sulfido complexes, $\left[\mathrm{Au}_{12}(\mu-\mathrm{dppm})_{6}\left(\mu_{3}-\mathrm{S}\right)_{4}\right]^{4+}$ and $\left[\mathrm{Au}_{10}\left\{\mu-\mathrm{Ph}_{2} \mathrm{PN}\left({ }^{\mathrm{n}} \mathrm{Pr}\right) \mathrm{PPh}_{2}\right\}_{4}\left(\mu_{3}-\mathrm{S}\right)_{4}\right]^{2+}$ (Scheme 5) [11]. Both series of complexes display strong luminescence upon photoexcitation in the solid state and in fluid solutions. The low-energy emissions were tentatively assigned to result from a LMCT ( $\mathrm{S}^{2-} \rightarrow \mathrm{Au}$ ) excited state, mixed with a metal-centered $(5 \mathrm{~d} \rightarrow 6 \mathrm{~s} / 6 \mathrm{p})$ state modified by $\mathrm{Au}-\mathrm{Au}$ interactions.

\section{SPECTROCHEMICAL AND LUMINESCENCE CHEMOSENSING}

It is believed that with a sound fundamental understanding on the emission origin of $\mathrm{d}^{10}$ polynuclear metal complexes, various versatile chemosensors and luminescence signalling devices based on metal-metal interactions could be designed. Recently, we reported the luminescence and ion-binding 

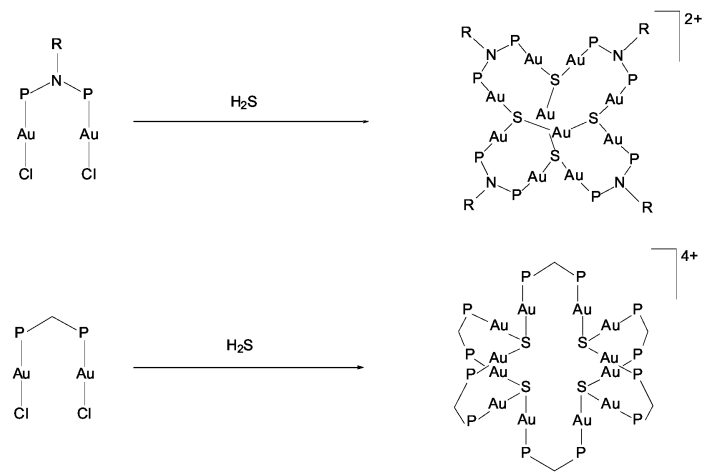

\section{Scheme 5}

properties of dinuclear gold(I) crown-ether complexes $\left[\mathrm{Au}_{2}(\mathrm{P}-\mathrm{P})(\mathrm{S}-\mathrm{B} 15 \mathrm{C} 5)_{2}\right][\mathrm{P}-\mathrm{P}=$ bis(diphenylphosphino)methane (dppm), bis(dicyclohexylphosphino)methane (dcpm); HS-B15C5 = 4'-mercaptomonobenzo-15-crown-5] [12]. The UV-vis absorption spectra of both complexes in $\mathrm{CH}_{2} \mathrm{Cl}_{2}-\mathrm{MeOH}$ showed spectral changes upon addition of potassium ions. The absence of such changes for the crownfree complexes $\left[\mathrm{Au}_{2}(\mathrm{P}-\mathrm{P})\left\{\mathrm{S}_{-} \mathrm{C}_{6} \mathrm{H}_{4}\left(\mathrm{OCH}_{3}\right)_{2}-3,4\right\}_{2}\right]$ suggested that the spectral changes resulted from the encapsulation of potassium ion by the benzo-15-crown-5 units of the $\left[\mathrm{Au}_{2}(\mathrm{P}-\mathrm{P})(\mathrm{S}-\mathrm{B} 15 \mathrm{C} 5)_{2}\right]$. It is found that the complexes, $\left[\mathrm{Au}_{2}(\mathrm{dppm})(\mathrm{S}-\mathrm{B} 15 \mathrm{C} 5)_{2}\right]$ and $\left[\mathrm{Au}_{2}(\mathrm{dcpm})(\mathrm{S}-\mathrm{B} 15 \mathrm{C} 5)_{2}\right]$, form 1:1 adducts with potassium ion with $\log K$ values of 3.4 and 4.0, respectively. The emission spectrum shows a drop in intensity at ca. $502 \mathrm{~nm}$, with the concomitant formation of a new long-lived emission band at ca. 720 $\mathrm{nm}(0.2 \mu \mathrm{s})$ upon addition of potassium ions. However, such a change in emission spectral traces was absent for the crown-free analogs. Besides, despite the well-known binding of sodium ions by benzo15-crown-5 compounds, similar emission spectral changes were not observed when sodium ions were used instead of potassium ions. This is supportive of the sandwich binding of the potassium ion by the two benzo-15-crown-5 moieties of the same molecule (Fig. 2). It is believed that the binding of $\mathrm{K}^{+}$ion
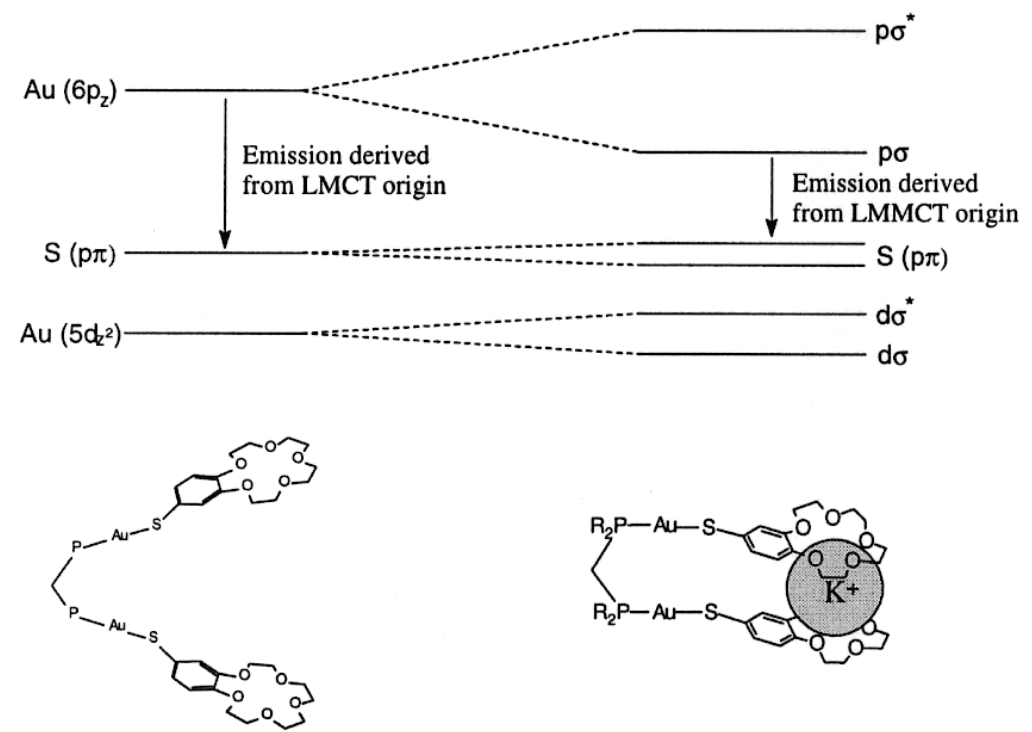

Absence of $\mathrm{K}^{+}$

Presence of $\mathrm{K}^{+}$

Fig. 2 A schematic representation of the orbital splittings in $\left[\mathrm{Au}_{2}(\mathrm{P}-\mathrm{P})(\mathrm{S}-\mathrm{B} 15 \mathrm{C} 5)_{2}\right]$ and its proposed structure in the absence and in the presence of potassium ion binding.

(C) 2001 IUPAC, Pure and Applied Chemistry 73, 543-548 
would bring the two gold(I) centers into close proximity with each other, resulting in some weak gold-gold interaction. It has been proposed that the low-energy emission band arises from a ligand to metal-metal charge transfer (LMMCT) $\left[\mathrm{RS}^{-} \rightarrow \mathrm{Au}_{2}\right]$ excited state, similar to that proposed for gold(I) phosphine thiolates [13].

\section{ACKNOWLEDGMENTS}

Financial support from the Research Grants Council and The University of Hong Kong is gratefully acknowledged.

\section{REFERENCES}

1. (a) A. P. Zipp. Coord. Chem. Rev. 84, 47 (1988); (b) D. M. Roundhill, H. B. Gray, C. M. Che. Acc. Chem. Res. 22, 55 (1989).

2. (a) J. V. Caspar. J. Am. Chem. Soc. 107, 6718 (1985); (b) P. D. Harvey and H. B. Gray. J. Am. Chem. Soc. 110, 2145 (1988); (c) C. M. Che, H. L. Kwong, V. W. W. Yam, K. C. Cho. J. Chem. Soc., Chem. Commun. 885 (1989); (d) C. King, J. C. Wang, N. I. Md. Khan, J. P. Fackler, Jr. Inorg. Chem. 27, 1672 (1988); (e) W. F. Fu, K. C. Chan, V. M. Miskowski, C. M. Che. Angew. Chem., Int. Ed. Engl. 38, 2783 (1999).

3. (a) H. Schmidbaur. Chem. Soc. Rev. 391 (1995); (b) P. Pyykkö. Chem Rev. 97, 597 (1997).

4. (a) V. W. W. Yam, W. K. Lee, T. L. Lai. Organometallics 12, 2383 (1993); (b) V. W. W. Yam, W. K. Lee, P. K. Y. Yeung, D. Phillips. J. Phys. Chem. 98, 7545 (1994); (c) V. W. W. Yam, W. K. Lee, K. K. Cheung, B. Crystall, D. Phillips. J. Chem. Soc., Dalton Trans. 3283 (1996); (d) V. W. W. Yam, W. K. M. Fung, M. T. Wong. Organometallics 16, 1772 (1997); (e) V. W. W. Yam, W. K. M. Fung, K. K. Cheung. J. Chem. Soc., Chem. Commun. 963 (1997); (f) V. W. W. Yam, W. K. M. Fung, K. K. Cheung. J. Clust. Sci. 10, 37 (1999).

5. V. W. W. Yam, W. K. M. Fung, K. K. Cheung. Angew. Chem., Int. Ed. Engl. 108, 1213 (1996).

6. (a) M. S. Wrighton and D. L. Morse. J. Am. Chem. Soc. 96, 998 (1974); (b) A. J. Lees. Chem. Rev. 87, 711 (1987); (e) D. J. Stufkens. Comments Inorg. Chem. 13, 359 (1992).

7. (a) M. I. Bruce, D. A. Harbourne, F. Waugh, F. G. A. Stone. J. Chem. Soc. (A) 356 (1968); (b) W. Beck, B. Niemer, J. Breimair, J. Heidrich. J. Organomet. Chem. 372, 79 (1987); (c) A. Wong and J. A. Gladysz. J. Am. Chem. Soc. 102, 4948 (1982).

8. (a) V. W. W. Yam, V. C. Y. Lau, K. K. Cheung. Organometallics 14, 2749 (1995); (b) V. W. W. Yam, V. C. Y. Lau, K. K. Cheung. Organometallics 15, 1740 (1996);

9. (a) V. W. W. Yam, S. H. F. Chong, K. K. Cheung. J. Chem. Soc., Chem. Commun. 2121 (1998); (b) V. W. W. Yam, S. H. F. Chong, C. C. Ko, K. K. Cheung. Organometallics 19, 5092 (2000).

10. (a) V. W. W. Yam, W. K. Lee, T. F. Lai. J. Chem. Soc., Chem. Commun. 1571 (1993); (b) C. R. Wang, K. K. W. Lo, V. W. W. Yam. Chem. Phys. Lett. 262, 91 (1996); (c) V. W. W. Yam, K. K. W. Lo, K. K. Cheung. Inorg. Chem. 35, 3459 (1996); (d) V. W. W. Yam, K. K. W. Lo. Comments Inorg. Chem. 19, 209 (1997); (e) V. W. W. Yam, K. K. W. Lo. Chem. Soc. Rev. 28, 323 (1999).

11. (a) V. W. W. Yam, E. C. C. Cheng, K. K. Cheung. Angew. Chem., Int. Ed. Engl. 38, 197 (1999); (b) V. W. W. Yam, E. C. C. Cheng, Z. Y. Zhou. Angew. Chem., Int. Ed. Engl. 39, 1683 (2000).

12. V. W. W. Yam, C. K. Li, C. L. Chan. Angew. Chem., Int. Ed. Engl. 37, 2857 (1998).

13. J. M. Forward, D. Bohmann, J. P. Fackler, Jr., R. J. Staples. Inorg. Chem. 34, 6330 (1995). 